\title{
What impact do chronic disease self- management support interventions have on health inequity gaps related to socioeconomic status: a systematic review
}

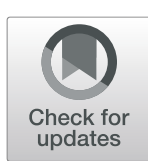

Ruth Hardman ${ }^{1,2^{*}}$ (D, Stephen Begg ${ }^{3}$ and Evelien Spelten ${ }^{1}$

\begin{abstract}
Background: The social gradient in chronic disease (CD) is well-documented, and the ability to effectively selfmanage is crucial to reducing morbidity and mortality from CD. This systematic review aimed to assess the moderating effect of socioeconomic status on self-management support (SMS) interventions in relation to participation, retention and post-intervention outcomes.
\end{abstract}

Methods: Six databases were searched for studies of any design published until December 2018. Eligible studies reported on outcomes from SMS interventions for adults with chronic disease, where socioeconomic status was recorded and a between-groups comparison on SES was made. Possible outcomes were participation rates, retention rates and clinical or behavioural post-intervention results.

Results: Nineteen studies were retrieved, including five studies on participation, five on attrition and nine studies reporting on outcomes following SMS intervention. All participation studies reported reduced engagement in low SES cohorts. Studies assessing retention and post-intervention outcomes had variable results, related to the diversity of interventions. A reduction in health disparity was seen in longer interventions that were individually tailored. Most studies did not provide a theoretical justification for the intervention being investigated, although four studies referred to Bandura's concept of self-efficacy.

Conclusions: The limited research suggests that socioeconomic status does moderate the efficacy of SMS interventions, such that without careful tailoring and direct targeting of barriers to self-management, SMS may exacerbate the social gradient in chronic disease outcomes. Screening for patient disadvantage or workload, rather than simply recording SES, may increase the chances of tailored interventions being directed to those most likely to benefit from them. Future interventions for low SES populations should consider focussing more on treatment burden and patient capacity.

Trial registration: PROSPERO registration CRD42019124760. Registration date 17/4/19.

Keywords: Self-management, Socioeconomic status, Health inequity, Patient capacity, Chronic disease

\footnotetext{
* Correspondence: r.hardman@latrobe.edu.au

'La Trobe University Rural Health School, 471 Benetook Avenue, Mildura, Victoria 3500, Australia

${ }^{2}$ Sunraysia Community Health Services, 137 Thirteenth Street, Mildura, Victoria 3500, Australia

Full list of author information is available at the end of the article
}

(c) The Author(s). 2020 Open Access This article is licensed under a Creative Commons Attribution 4.0 International License, which permits use, sharing, adaptation, distribution and reproduction in any medium or format, as long as you give appropriate credit to the original author(s) and the source, provide a link to the Creative Commons licence, and indicate if changes were made. The images or other third party material in this article are included in the article's Creative Commons licence, unless indicated otherwise in a credit line to the material. If material is not included in the article's Creative Commons licence and your intended use is not permitted by statutory regulation or exceeds the permitted use, you will need to obtain permission directly from the copyright holder. To view a copy of this licence, visit http://creativecommons.org/licenses/by/4.0/ The Creative Commons Public Domain Dedication waiver (http://creativecommons.org/publicdomain/zero/1.0/) applies to the data made available in this article, unless otherwise stated in a credit line to the data. 


\section{Background}

Chronic health conditions are increasingly common, with some population groups, such as those of lower socioeconomic status (SES) having both a greater incidence of chronic disease and a poorer prognosis [1-3]. The long-term nature of these conditions means that the patient is largely responsible for day-to-day disease management $[4,5]$ and since many chronic conditions are lifestyle-related [6], the quality of patient selfmanagement is important. Self-management support (SMS) approaches have been developed to give people the skills to more effectively manage their health. These interventions involve both education and behaviour change strategies to address the medical, physical, emotional and social challenges associated with $\mathrm{CD}$, aiming to help the person adapt to their changed circumstances whilst still leading a meaningful life $[4,5,7]$.

Although SMS interventions are now widespread, outcomes have been mixed, with the benefits being limited to short-term improvements in psychological variables such as self-efficacy, rather than sustained clinical or behavioural changes [4, 6, 8, 9]. Most SMS interventions are theoretically grounded in Bandura's concept of selfefficacy [5] and utilise specific techniques to enhance self-efficacy $[5-7,10,11]$. Self-efficacy theory refers to an individual's belief or confidence in their capacity to undertake tasks or achieve goals, which can translate into health behaviour change and by implication, improved health status $[4,5]$.

Persisting questions remain, however, about the effectiveness of SMS in low SES and other disadvantaged groups. The original SMS trials were conducted in selfselected, higher SES populations $[4,6,10]$ and studies in disadvantaged populations have reported poorer outcomes and lower levels of adherence [12, 13]. Several writers have theorised that the individual patient focus of SMS limits its effectiveness in these groups. By prioritising individual self-efficacy and activation, the potential barriers to self-management within the patient's wider social context (e.g. literacy, resources, social supports) are ignored [6,10,11, 14, 15]. Although the dominant role of the social determinants of health is acknowledged in CD epidemiology, their influence on treatment engagement is rarely addressed [15].

Effective chronic disease (CD) management should include both an improvement in overall population health and a reduction in health inequities [16-18]. An intervention that appears more effective in a better-off population may widen the disparity gap, and there are strong suggestions that individually-focussed 'downstream' interventions, such as SMS, can increase disparity [17, 19, 20]. Specific targeting of disadvantaged groups is one way to deal with inequity, and tailored SMS approaches for these groups have been trialled, but systematic reviews have shown inconsistent and dose-dependent benefits [13, 21]. In addition, such interventions may have positive outcomes, but still not address the disparity gap [18].

Although there are suggestions that SMS interventions may be less effective in low SES groups, this can only be determined by comparing SMS outcomes between more and less advantaged groups. There have been no previous reviews on this topic, despite many researchers stressing the importance of addressing and quantifying the equity gap in CD [18-20, 22, 23]. This is partly due to statistical challenges, since the evidence will emerge from subgroup analyses [19, 24, 25]. However, given the strong connection between the social determinants of health and health outcomes, subgroup analyses need not be post-hoc data dredging but can be planned and valid approaches to answering these questions [26-28].

This review aims to examine studies that have looked at differences between socioeconomic groups undergoing SMS interventions, in order to answer the following questions: 1 . Is there evidence that SES influences participation rates in SMS interventions? 2. Is there evidence that SES influences rates of retention or dropout from SMS interventions? 3: Is there evidence that SES affects clinical, behavioural or other specified outcomes following SMS interventions?

\section{Methods}

\section{Search strategy and data abstraction}

We conducted a systematic review of the literature using the PRISMA reporting guidelines [29] to structure the report. We searched for full-text articles in English to December 2018 in the following databases: Cochrane database; PubMed; Cinahl; Embase; Proquest and Psychinfo. The search terms covered the following areas, using MeSH terms and synonyms: [1] Chronic condition, including diabetes, cardiovascular disease, musculoskeletal conditions and chronic pulmonary disease [2]; Self-management [3]; Socio-economic status, including associated terms such as inequity, disparity, 'vulnerable groups'; and [4] Terms related to outcomes, efficacy, retention or participation. The PubMed search strategy is available in Additional file 1. No date filter was employed in order to obtain the widest possible search. In the course of the search thirteen related systematic reviews were located and their references were screened resulting in seven additional papers.

\section{Inclusion criteria}

Inclusion and exclusion criteria are outlined in Table 1. We looked for four main chronic conditions: cardiovascular disease (CVD), musculoskeletal conditions (MSK), pulmonary disease (COPD) and diabetes. All these conditions contribute significantly to the burden of disease and share many common risk factors. We included 
Table 1 Inclusion/exclusion criteria

\begin{tabular}{|c|c|c|}
\hline $\mathrm{PICO}$ & Inclusion Criteria & Exclusion Criteria \\
\hline \multirow[t]{3}{*}{ Population } & Over 18 years & \\
\hline & $\begin{array}{l}\text { Diagnosed with diabetes, COPD, cardiovascular disease, chronic } \\
\text { musculoskeletal pain and any additional comorbidities }\end{array}$ & At-risk patients (e.g. prediabetes) \\
\hline & SES described in terms of education, income, area or occupation. & $\begin{array}{l}\text { 'Disadvantaged' (e.g. ethnic minority) population } \\
\text { without quantifiable reference to SES. }\end{array}$ \\
\hline Intervention & $\begin{array}{l}\text { Includes a self-management support intervention incorporating } \\
\text { at least } 3 \text { recognised elements of SM [7] }\end{array}$ & $\begin{array}{l}\text { Single-component SMS intervention (e.g. education, } \\
\text { medication adherence only). }\end{array}$ \\
\hline Comparison & $\begin{array}{l}\text { Includes analysis of whether the response to the intervention } \\
\text { differs according to SES. }\end{array}$ & $\begin{array}{l}\text { No measurement of SES disparity in reporting of } \\
\text { outcomes. }\end{array}$ \\
\hline Outcome & $\begin{array}{l}\text { Reporting of outcomes which may be clinical, behavioural, psychosocial } \\
\text { or related to participation/attrition. }\end{array}$ & \\
\hline
\end{tabular}

studies of co/multimorbidity since this is representative of the $\mathrm{CD}$ population. A decision was made to focus only on socio-economic status (SES), which has welldocumented and consistent effects on chronic disease, rather than on other WHO PROGRESS+ factors such as gender and ethnicity, which can vary between countries [19]. All studies needed to provide a comparison between a less and more advantaged group, based on income, education or socioeconomic area. Comparisons based on literacy or ethnicity were only included if there was a quantifiable relationship between these variables and other SES measures. As well as post-intervention outcomes such as behavioural or clinical changes, outcomes related to participation and dropout were included to fully capture potential areas of disparity. Study designs could include randomised controlled trials with subgroup analyses, pre-post designs, cross-sectional or longitudinal data analyses.
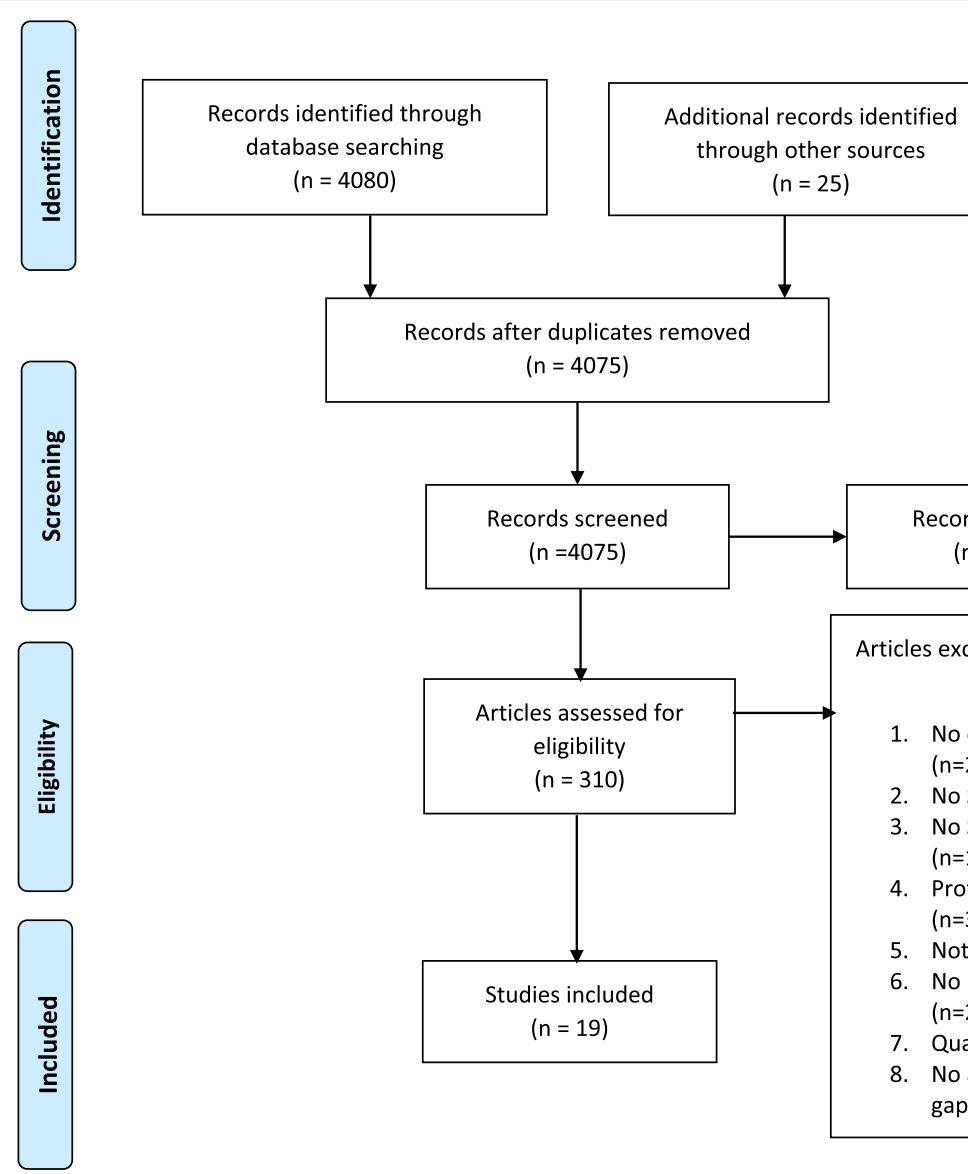

Records after duplicates removed

( $n=4075$ )

Studies included $(n=19)$
Records excluded ( $n=3772$ )

Articles excluded, with reasons $(n=291)$

1. No chronic disease $(n=22)$

2. No SES $(n=30)$

3. No SM intervention $(n=115)$

4. Protocol/design study $(n=32)$

5. Not full-text $(n=23)$

6. No English translation $(n=2)$

7. Qualitative study $(n=30)$

8. No analysis disparity gap $(n=37)$ 


\section{Search outcomes}

Title and abstract screening reduced the number of papers to 310. Articles were excluded according to the criteria outlined in Table 1. Common reasons for exclusion were no SMS intervention (e.g. studies of self-care or adherence behaviours); SES not quantified, and no measurement of SES disparity. A full list of reasons for exclusion of the 291 full-text articles is available in Additional file 2. Figure 1 illustrates the search process undertaken. One reviewer $(\mathrm{RH})$ completed the initial search and a second reviewer (ES) independently assessed the final papers to ensure agreement on inclusion criteria. Nineteen studies were included in the review.

\section{Data abstraction}

The data was summarised on the setting, study design, type of $\mathrm{CD}$, sample size, description of intervention and control, outcomes or variables measured, follow-up time, results and study quality (Table 2 and Table 3). Table 4 and Table 5 summarises data related specifically to SES and disparity, including the theory behind the SM intervention (or study question for participation/attrition studies), intervention description, SES adaptations made, SES status of population, results in relation to SES, dropout rates and overall impact on SES disparity. Related papers were retrieved to provide additional data about the population or intervention as needed [31-38].

Quality analysis was undertaken using the Joanna Briggs Institute checklists [30] for randomised controlled trials (RCTs) and observational studies, and the Sun/ Oxman criteria $[27,28]$ for subgroup analyses.

\section{Data synthesis}

No meta-analysis was possible due to the diversity of study designs, interventions and outcome variables.

\section{Results}

\section{Key study characteristics}

Nineteen studies were identified, all published in English. Five studies looked at participation in SMS; five studied attrition from SMS programmes and nine assessed outcomes from SMS interventions. Interventions were very diverse, ranging from studies of the group-based Stanford Chronic Disease Self-Management Programme (CDSMP - 4 studies) to highly tailored 1-1 interventions. Table 2 and Table 3 details the main features of all studies.

\section{Methodological quality}

Most studies were of moderate to good quality although two RCTs [39, 40] and three subgroup analyses [39-41] rated poorly. A summary of quality ratings is included in
Table 2 and Table 3 and a detailed table describing how each study was assessed is available in Additional file 3.

Responses to study questions

1. Is there evidence that SES influences participation rates in SMS interventions?

Four cross-sectional studies and one cohort study looked at initial participation in SMS programmes. All were large population surveys ranging from 2600 to 80 , 000 people. There were three reports on diabetes SMS education programmes [42-44], one on the Stanford CDSMP [45] and the final study examined recruitment to an internet diabetes SMS programme [46]. In all studies, low SES (as measured by education, income or location) was significantly and consistently associated with lower levels of participation, suggesting that disparity in CDSM starts here. Some studies $[43,45]$ suggested that this imbalance was related to course availability, cost or marketing strategies. However, the studies which did match attendance to course availability and cost [42, 44] found that this did not influence participation in the low SES population. Glasgow [46] also compared participation rates in a self-selected (via media advertising) population to a referred population and found even greater disparity. As well as being of higher SES, the selfselected participants were those at lowest risk and least in need of the intervention.

There is consistent evidence that low SES is associated with lower levels of participation in SMS interventions, and some evidence that this is unrelated to access to SMS interventions.

2. Is there evidence that SES influences rates of retention or dropout from SMS interventions?

Five studies examined attrition: two cross-sectional studies and three RCTs with subgroup analysis, with sample sizes from 100 to 300. Two RCTs [41, 47] were of more advantaged populations. Of these, one reported low (22.8\%) completion rates of the Stanford CDSMP [41], but predictors were related to poor physical health rather than SES. Since this was a high-risk multimorbid rather than a low SES population, dropout likely reflects increased treatment burden, as noted in other multimorbid populations [48]. The second study [47], of a diverse urban population, reported no difference in use of a supported internet programme in terms of SES (education). This intervention had been carefully tailored to maximise engagement across population groups and included extensive community involvement in the design process. Three studies [49-51] focussed on low SES populations. Two cross-sectional studies $[49,50]$ reported that dropout rates correlated to social stressors and lack of job 


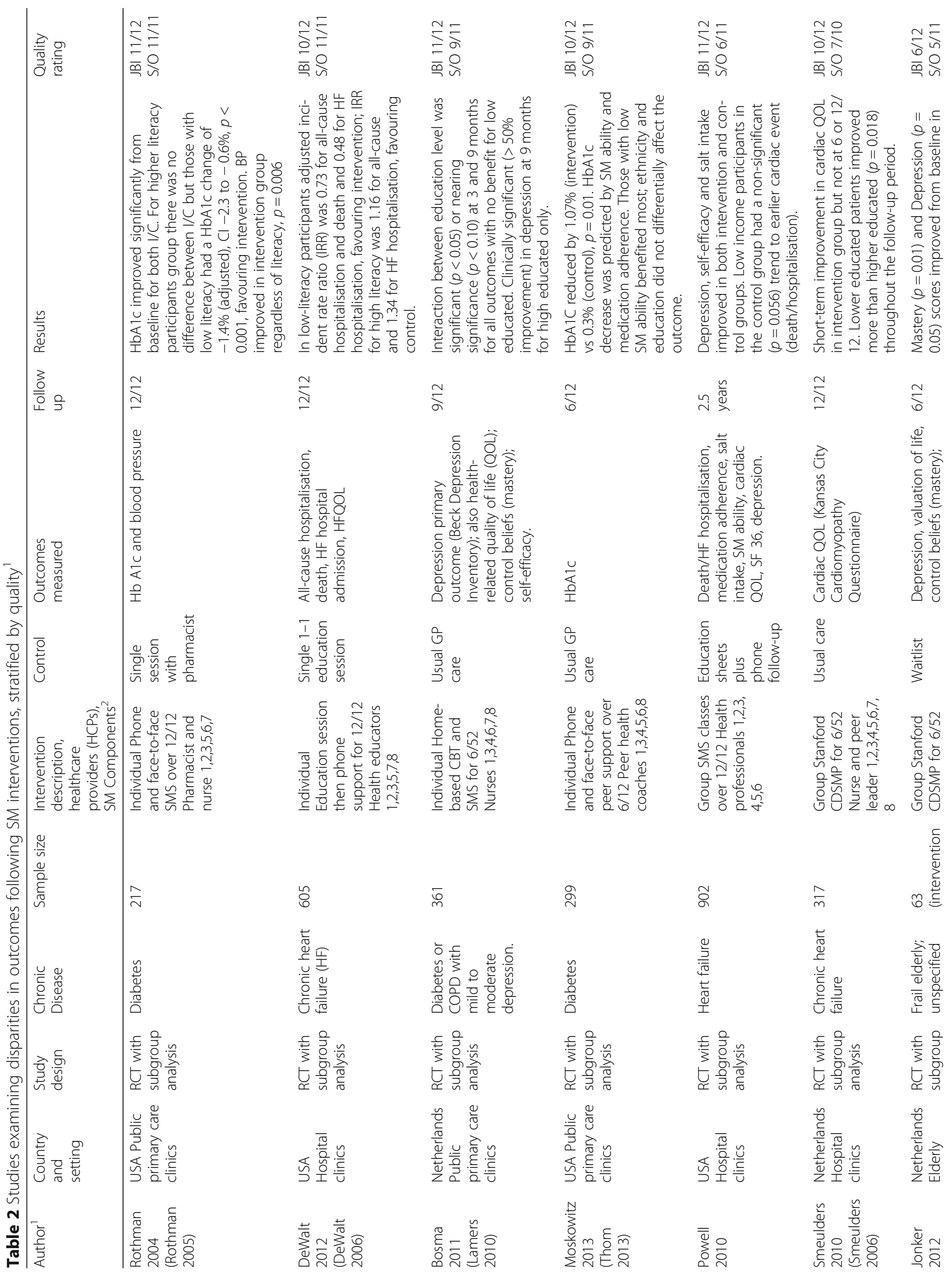




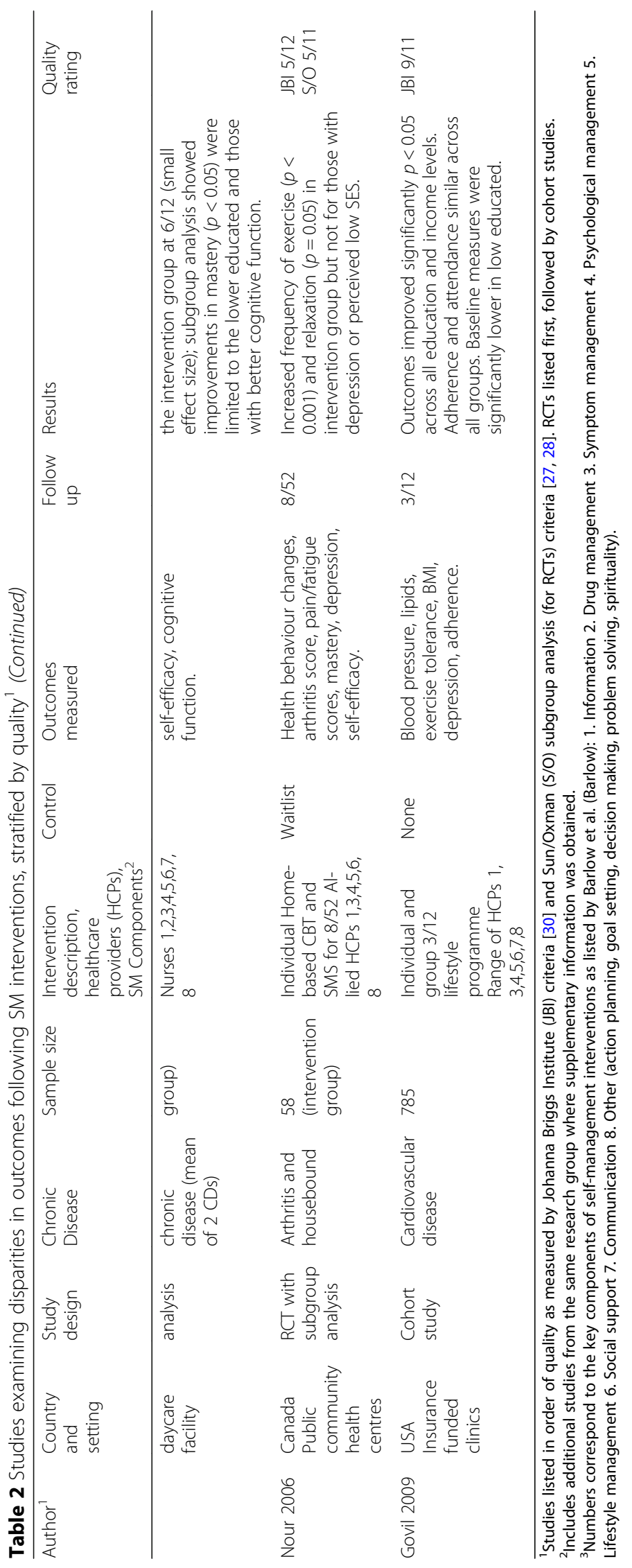




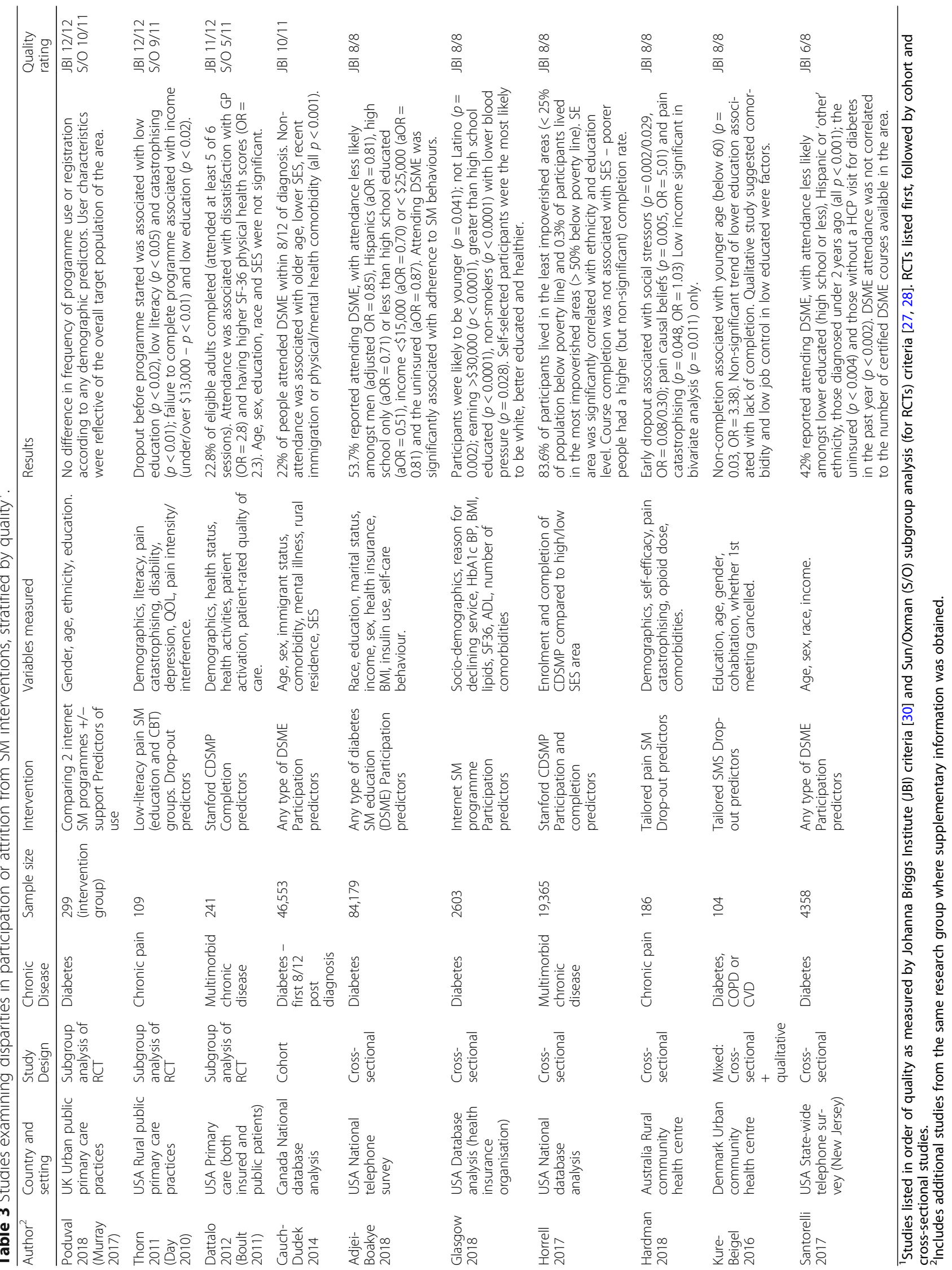




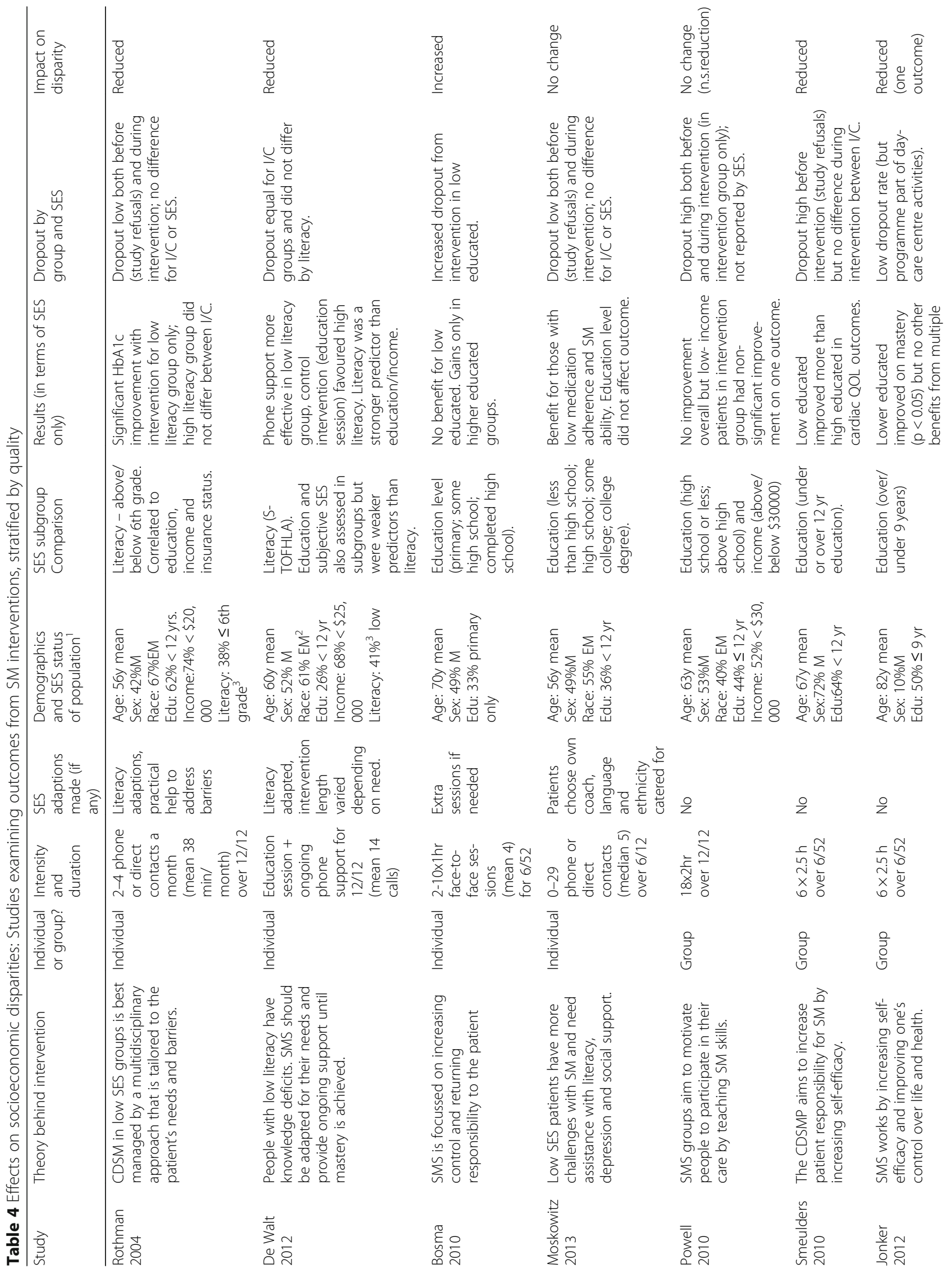




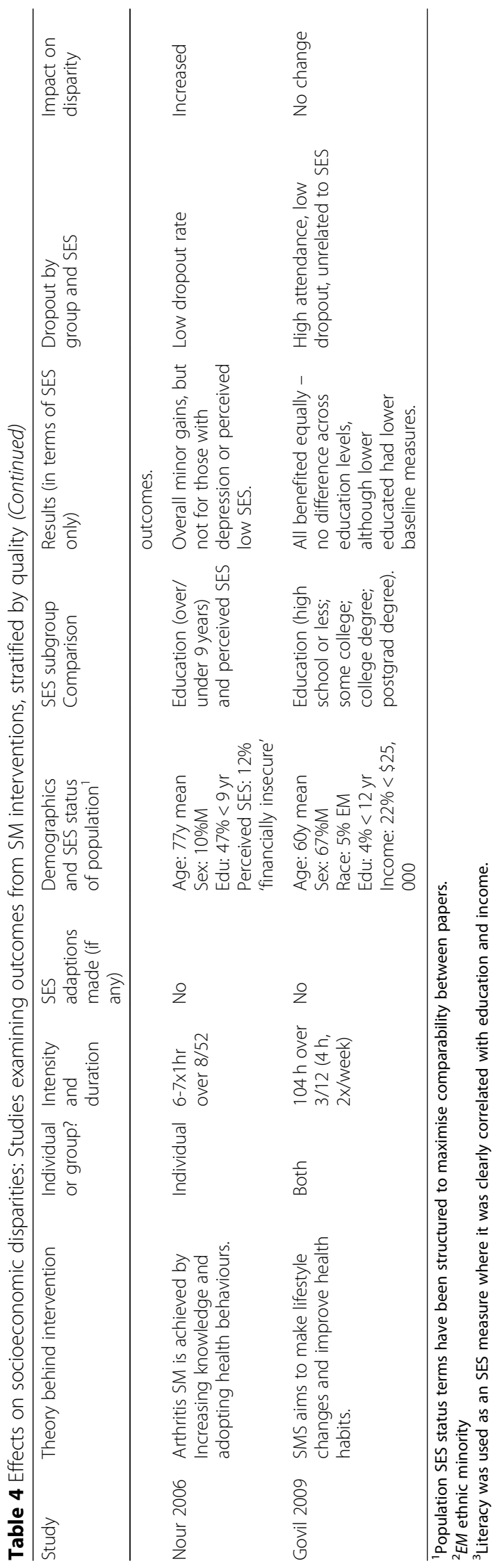




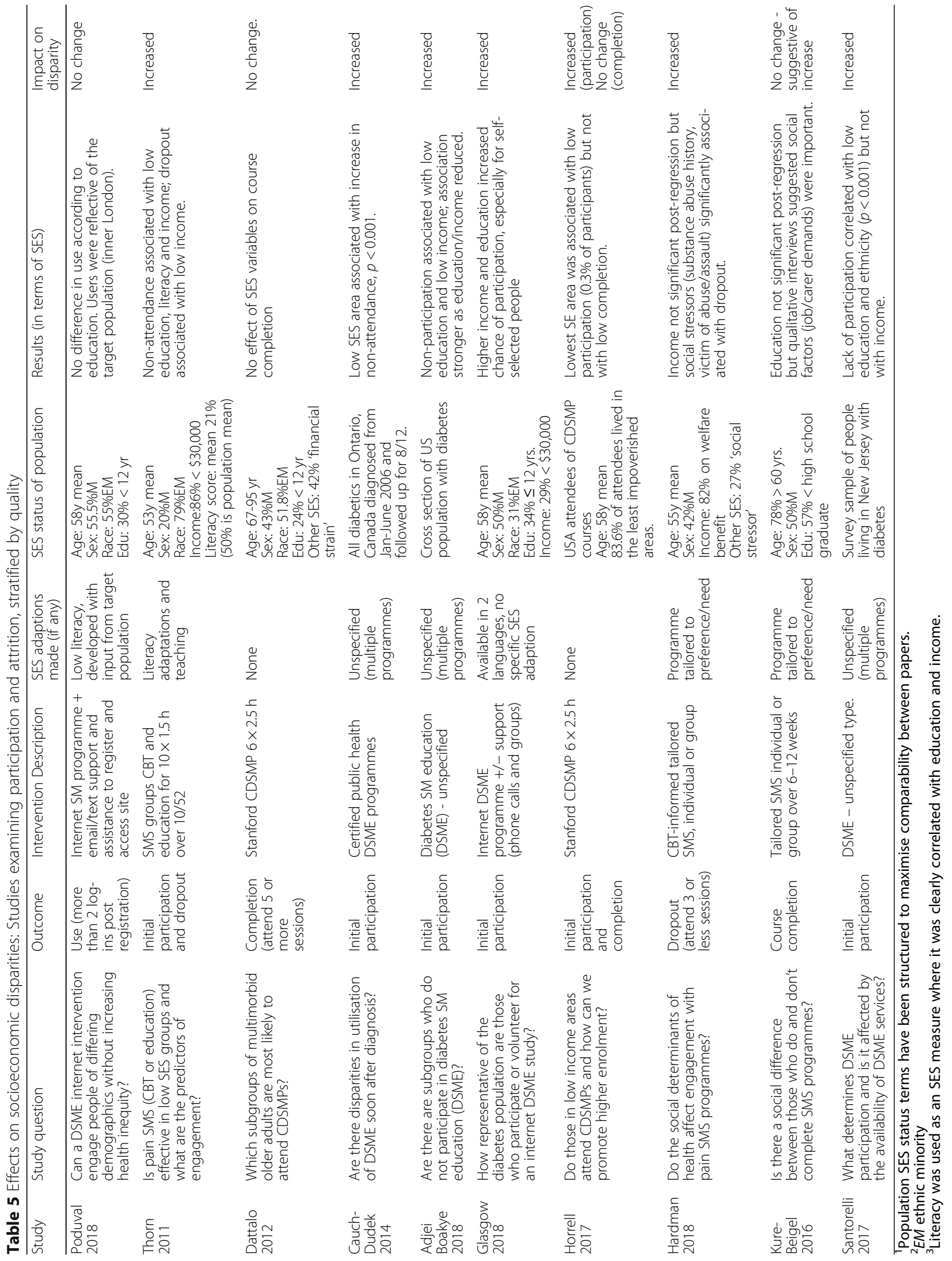


flexibility, suggesting that attrition within a low SES population may be influenced by socioeconomic factors that are not captured by education or income alone. Finally, a small RCT [51] of a tailored group programme found that high levels of dropout were significantly associated with low income and education. By contrast, Horrell et al. [45] noted that although SES area predicted enrolment in the Stanford CDSMP, it did not affect rates of completion.

SES is not consistently associated with dropout from SMS interventions. SES may be one of a number of factors associated with programme attrition, as suggested by qualitative studies on this topic [52].

3. Is there evidence that SES affects clinical, behavioural or other specified outcomes following SMS interventions?

Nine studies looked at outcomes following SMS interventions, with four describing group interventions (including 2 of the Stanford CDSMP) and five individual [1] interventions. Only two of the RCTs [53, 54] were sufficiently powered for subgroup analysis and most had follow-up periods of 6 months or less.

Three of the nine studies featured outlier populations (in terms of age, sex and/or level of disadvantage), including the two lower-quality studies $[39,40]$ and the cohort study [55]. The findings from these studies may not be reliable or relevant to the wider low SES population.

The remaining six studies, of moderate to high quality, described broadly similar populations in terms of age, sex, education and income. Of these studies, one reported increased disparity following the intervention; two reported no change; and three studies reported a reduction in SES disparity.

Three of the studies, all individual interventions, described programmes specifically tailored for low SES groups, including extra supports and literacy adaptations. These included a 6-month peer support programme [56] and two 12-month phone support programmes [53, 57] (conducted by the same research group, but with different chronic diseases and interventions). All studies reported clinically and statistically significant changes in either hospitalisation rates [53] or HbA1c $[56,57]$ in favour of the intervention. Two of the studies also reported a reduction in SES disparity from the intervention, with low-literacy patients experiencing greater benefit from the intervention than their higher literacy counterparts. In an already lowSES population, this was found to be a stronger predictor than income or education. The third study (the peer support programme) reported no change in disparity, with benefits across all education levels and the greatest benefit experienced by those with poorer medication adherence and self-management ability.
The remaining studies - comprising one individual and two group interventions - did not provide specific tailoring for low SES participants. The individual intervention [58], a 6-week CBT programme designed to increase self-efficacy, found clinically significant improvements in depression only in the higher educated, with no change and higher rates of dropout in the lower educated. The group interventions, which were both for people with heart failure, included the 6-week CDSMP and a year-long SMS group programme. The CDSMP study did show short-term benefits as compared to usual care, but no overall gains at 6 or 12 months. The lower educated patients did better than their higher educated counterparts in terms of cardiac quality of life (QOL) ( $p=0.018)$ over 12 months, suggesting a reduction in SES disparity, although it was not clear whether this was clinically significant. The second group programme [54] used an active education control and found no additional benefit from an SMS group. Low-income participants receiving the intervention did have a longer time to cardiac event (death or hospitalisation), but this was not statistically significant. Overall there was no change in SES disparity, nor any added benefit from the intervention.

There is limited evidence to suggest that SES does affect outcomes following SMS interventions. Interventions that were tailored for low SES participants reported significant improvements in clinical outcomes, which in some cases also included a reduction in SES disparity following the intervention.

\section{Discussion}

\section{Main findings}

This systematic review of disparities related to SMS interventions has reinforced observations [18-20, 22, 25] that there is a lack of research in this area. Although many studies of low SES groups have been undertaken, very few have focused on whether the outcomes compare favourably to those in higher SES groups. There are practical and statistical challenges in comparing population subgroups. Many studies had SES groupings that were fairly homogenous, limiting the ability to compare outcomes within the analysis, and almost all subgroup analyses were insufficiently powered. Larger studies and co-operation between different study populations are needed so that there is a more distinct contrast between SES levels across groups.

Responses to study questions.

1. Is there evidence that SES influences participation rates in SMS interventions?

This review confirms that low SES groups are significantly less likely to participate in SMS interventions 
[42-46]. Thus, healthcare disparity is increasing before an intervention even commences. In order to reach those who need the intervention, targeted recruitment and retention strategies will be needed. Self-selection runs the risk of spending limited resources on those who need them least [46].

2. Is there evidence that SES influences rates of retention or dropout from SMS interventions?

The findings in relation to retention and dropout are less clear-cut, with few studies and small sample sizes. Social factors do appear to be important [49-51], although a simple measure of SES may not capture the barriers to engagement.

3. Is there evidence that SES affects clinical, behavioural or other specified outcomes following SMS interventions?

With the limited number of high-quality studies available, there was some evidence that SES does affect outcomes following SMS interventions, depending on the type of intervention on offer. No trends were observed in terms of the SM components, which varied little between studies, or the type of service providers involved.

Programme structure (group or individual) did seem to affect both dropout rates and outcomes, with fewer benefits observed in the group interventions. In the few programmes that recorded dropout by SES, it appeared that attrition was also greater from group programmes (see Table 4 and Table 5). High rates of dropout from group programmes have been reported in several reviews of $C D$ interventions in low SES and other vulnerable groups [21, 59], while other reviews [13, 60, 61] have noted that individually tailored interventions appear to reduce disparity. Other authors have noted that although group programmes provide beneficial social support and peer modelling [5], they can also present many barriers to a low SES population who may have less flexibility in terms of work, transport or caring demands [21,59]. In the current review, interventions over longer time periods (6-12 months) also seemed to be more effective at reducing disparity $[53,56,57]$, consistent with a CD review on similar populations [13].

\section{Interpretation of findings}

\section{1. 'Low SES' is a heterogenous group}

This review suggests that SMS interventions may impact differently on low SES populations, and that more individualised treatment over longer time periods may be needed. Some writers have suggested that SES could be used as a 'high risk' predictor to identify those needing an earlier or more intensive intervention [23, 62], although this encompasses a large population group and has significant resource implications, emphasising the need for appropriate targeting of interventions.

Data from the current review indicates that low SES groups are heterogeneous, with additional factors such as literacy, social stressors and social capital influencing SM ability, engagement, health outcomes [49, 50, 53, 57] and thus disparity. Therefore, some low SES groups may benefit simply from better marketing of and access to generic SM courses [45] and lower-level interventions, while others will require a more intensive, tailored approach. The ability to accurately identify these groups, perhaps by using a triage instrument, could lead to more effective resource allocation, increased participation and better outcomes in terms of both efficacy and equity.

2. Are self-management mechanisms different in low SES populations?

Few studies reviewed described the theory behind the proposed SMS intervention, as noted in other reviews of SMS [12, 63], although several referred to the role of self-efficacy [40, 54, 58, 64], as described in Bandura's social-cognitive theory $[4,5]$. The studies which targeted a low SES or otherwise diverse population did note particular challenges for disadvantaged groups in terms of knowledge or literacy $[47,53,56,57]$, and those which adapted to these challenges often had better outcomes. In contrast, 'one size fits all' programmes $[45,46,54,58]$ had fewer benefits, and in some cases increased disparity.

SMS approaches informed only by self-efficacy have been criticised as overly individualistic $[10,11,15]$ and it has been observed that the relationship between selfefficacy and self-management ability is weaker in vulnerable groups [65], indicating that other barriers play an important part. Furthermore, since the development of self-efficacy depends both on one's behaviour and on social/environmental feedback [66], several authors [11, 58] have suggested that increasing self-efficacy may be harder if environmental feedback (e.g. job or housing insecurity) negates a belief in control over one's circumstances.

3. What other factors are important for selfmanagement in low SES groups?

This suggests that for SMS interventions to be effective in low SES populations, attention should be paid to other factors that influence self-management ability. Health provider/system issues [67, 68]; resources (literacy, financial, job/carer demands) [67, 69-71]; and condition demands 
(multimorbidity, treatment burden) [48, 71, 72] have been consistently identified in qualitative reviews as barriers to self-management. Each of these factors will impact disproportionately on a low SES population. Health providers/ systems can be less accessible due to cost, literacy levels and a limited understanding of the social determinants of health by providers $[67,68]$. Although few studies of SM in disadvantaged populations look at interventions at the health provider/system level $[18,21]$, it would seem a potentially effective way to reduce disparity without increasing the patient's treatment burden.

Barriers related to resources and condition demands are far greater for the low SES population [73-75], who have fewer financial and social resources; higher levels of overall social complexity (job/housing insecurity, family demands, trauma history [3]); and higher rates of multimorbidity at earlier ages [76]. They experience both more disease-related workload (treatment burden) and non-disease workload (life burden) [73, 77]. Unfortunately, many SMS interventions, especially those requiring regular attendances or homework, will increase workload. Approaches that reduce patient workload or increase access to resources are rarely tried, but are likely to be important in low SES groups [73]. Phone consultations, problem-solving of specific barriers, integrating healthcare with social services and directing interventions toward healthcare practitioners rather than individual patients can all reduce treatment burden and maximise resources. Coventry [76], in a qualitative study of SM and multimorbidity, identifies three factors required for engagement in SM: capacity (resources, knowledge and energy); responsibility (shared understanding between the patient and provider about how to manage the treatment workload) and motivation. All three are negatively impacted by low SES, yet many SMS interventions [10] aim to increase motivation without recognising responsibility or capacity, and thus may contribute to increasing disparity in low SES groups.

\section{Strengths and limitations}

This review identifies important gaps in knowledge and potential directions for future research. It reveals the assumptions informing SMS approaches and the inadequacy of using 'low SES' to define a population group. The study limitations include the lack of published research on disparity in SM interventions. It was difficult to conduct a comprehensive literature search of this topic because many subgroup analyses were a relatively small part of the overall paper. It is possible that some studies were missed that may have provided useful data. Meta-analysis was not possible due to the variety of studies available; therefore, no strong conclusions can be formed. In addition, the methodology of many of the studies prohibited causal inference: several studies were cross-sectional and most subgroup analyses were underpowered or did not formulate a priori hypotheses.

\section{Conclusion}

This review has identified several important themes in relation to self-management and socioeconomic disparity. First and most obviously, there is a great need for equity considerations to be included in $\mathrm{CD}$ studies, as advocated by Cochrane reviewers [22, 25]. Given the strength of evidence available about social determinants of health, it should be possible to establish a priori hypotheses and sample sizes sufficient for subgroup analysis (including the availability of relevant comparator groups) for many interventions.

Secondly, any intervention in a low SES or otherwise disadvantaged group should consider its theoretical basis. Social-contextual approaches, rather than selfefficacy approaches, may be more effective. Paying greater attention to the large and consistent body of qualitative studies on barriers to SM can provide both theoretical and practical guidance as to interventions that can address disparity. Approaches such as the $\mathrm{Cu}$ mulative Complexity Model [77], which is founded on patient burden-capacity balance, have much to offer.

Finally, levels of disadvantage vary, and there is a need for risk identification within the low SES population. For many people, improving access to simple SM interventions (e.g. assistance with childcare or transport, free programmes at community locations) may be all that is needed. For others - especially those with multimorbidity, poor literacy or social complexity - an individually tailored approach will be needed to be effective. Research to develop a risk assessment system may ensure that those most in need receive the greatest support as opposed to the current situation.

\section{Supplementary information}

Supplementary information accompanies this paper at https://doi.org/10. 1186/s12913-020-5010-4.

\section{Additional file 1}

Additional file 2.

Additional file 3.

\section{Abbreviations}

CD: Chronic disease; CDSMP: Chronic disease self-management programme; COPD: Chronic obstructive pulmonary disease; CVD: Cardiovascular disease; DSME: Diabetes self-management education; MSK: Musculoskeletal; RCTs: Randomised controlled trials; SES: Socioeconomic status; SM: Selfmanagement; SMS: Self-management support

\section{Acknowledgements}

Thanks to Ms. Nadia Wesolek, Sunraysia Community Health Services; and Dr. Kelly Naess, Sunraysia Community Health Services, for feedback on the manuscript. Thanks to Ms.

Elizabeth Lawrence, La Trobe University, for assistance with the systematic search strategy. 


\section{Authors' contributions}

$\mathrm{RH}$ conducted the initial search with assistance from ES. RH drafted the initial manuscript, and ES and SB edited and further developed the manuscript. All authors read and approved the final manuscript.

\section{Funding}

No funding was received for this study.

\section{Availability of data and materials}

Data sharing is not applicable to this article as no datasets were generated or analysed during the current study.

\section{Ethics approval and consent to participate}

Not applicable.

\section{Consent for publication}

Not applicable.

\section{Competing interests}

The authors declare that they have no competing interests.

\section{Author details}

${ }^{1}$ La Trobe University Rural Health School, 471 Benetook Avenue, Mildura, Victoria 3500, Australia. ${ }^{2}$ Sunraysia Community Health Services, 137 Thirteenth Street, Mildura, Victoria 3500, Australia. ${ }^{3}$ La Trobe Rural Health School, La Trobe University, PO Box 199, Bendigo, Victoria 3552, Australia.

\section{Received: 24 August 2019 Accepted: 19 February 2020}

Published online: 27 February 2020

\section{References}

1. Australian Institute of Health and Welfare. Australia's Health 2018. 16th ed. Canberra: AlHW; 2018

2. Marmot M. Health in an unequal world. Lancet. 2006;368(9552):2081-94.

3. Wilkinson R, Marmot M. Social Determinants of Health. Denmark: The Solid Facts; 2003.

4. Walker $\mathrm{C}$, Swerissen $\mathrm{H}$, Belfrage J. Self-management: its place in the management of chronic illnesses. Aust Health Rev. 2003;26(2):34-42.

5. Lorig K, Holman H. Self-management education: history, definition, outcomes, and mechanisms. Ann Behav Med. 2003;26(1):1-7.

6. Adams RJ. Improving health outcomes with better patient understanding and education. Risk manag. 2010;3:61-72.

7. Barlow J, Wright C, Sheasby J, Turner A, Hainsworth J. Self-management approaches for people with chronic conditions: a review. Patient Educ Couns. 2001:48:177-87

8. Taylor SJC, Pinnock H, Epiphaniou E, Pearce G, Parke HL, Schwappach A et al. A rapid synthesis of the evidence on interventions supporting selfmanagement for people with long-term conditions: PRISMS - practical systematic review of self-management support for long-term conditions. Southampton (UK): Health Services and Delivery Research; 2014.

9. Foster G, Taylor SJ, Eldridge SE, Ramsay J, Griffiths CJ. Self-management education programmes by lay leaders for people with chronic conditions. Cochrane Database Syst Rev. 2007:4:CD005108.

10. Greenhalgh T. Patient and public involvement in chronic illness: beyond the expert patient. Br Med J. 2009;338:1-9.

11. Kendall E, Rogers A. Extinguishing the social?: state sponsored self-care policy and the chronic disease self-management Programme. Disabil Soc. 2007;22(2):129-43.

12. Van Hecke A, Heinen M, Fernandez-Ortega $P$, Graue M, Hendriks JM, Hoy B, et al. Systematic literature review on effectiveness of self-management support interventions in patients with chronic conditions and low socioeconomic status. J Adv Nurs. 2017:73(4):775-93.

13. Glazier RH, Bajcar J, Kennie NR, Willson K. A systematic review of interventions to improve diabetes care in socially disadvantaged populations. Diabetes Care. 2006;29(7):1675-88.

14. Furler J, Harris M, Rogers A. Equity and long-term condition selfmanagement. Chronic Illness. 2011;7(1):3-5.

15. Harvey PW, Docherty BM. Sisyphus and self-management: the chronic condition self-management paradox. Aust Health Rev. 2007;31(2):184-92.
16. Williams D, Costa M, Odunlami A, Mohammed S. Moving upstream: how interventions that address the social determinants of health can improve health and reduce disparities. J Public Health Manag Pract. 2008;14:S8-17.

17. White M, Adams J, Heywood P. How and why do interventions that increase health overall widen inequalities within populations? In: Babones S, editor. Social inequality and public health. Bristol: Policy Press; 2009.

18. Borkhoff CM, Wieland ML, Myasoedova E, Ahmad Z, Welch V, Hawker GA, et al. Reaching those most in need: a scoping review of interventions to improve health care quality for disadvantaged populations with osteoarthritis. Arthritis Care Res. 2011;63(1):39-52.

19. Lorenc T, Petticrew M, Welch $V$, Tugwell $P$. What types of interventions generate inequalities? Evidence from systematic reviews. J Epidemiol Community Health. 2013;67(2):190-3.

20. Jepson RG, Harris FM, Platt S, Tannahill C. The effectiveness of interventions to change six health behaviours: a review of reviews. BMC Public Health. 2010;10:538

21. Eakin EG, Bull SS, Glasgow RE, Mason M. Reaching those most in need: a review of diabetes self-management interventions in disadvantaged populations. Diabetes Metab Res Rev. 2002;18(1):26-35.

22. Tugwell $P$, Maxwell L, Welch V, Kristjansson E, Petticrew M, Wells G, et al. Is health equity considered in systematic reviews of the Cochrane musculoskeletal group? Arthritis Rheum. 2008;59(11):1603-10.

23. Beauchamp A, Peeters A, Tonkin A, Turrell G. Best practice for prevention and treatment of cardiovascular disease through an equity lens: a review. Eur J Cardiovasc Prev Rehabil. 2010;17(5):599-606.

24. Petticrew $M$, Welch $V$, Tugwell P. 'It is surely a great criticism of our profession...' The next 20 years of equity-focused systematic reviews. $J$ Epidemiol Community Health. 2014;68(4):291-2.

25. Welch V, Tugwell P, Petticrew M, de Montigny J, Ueffing E, Kristjansson B, et al. How effects on health equity are assessed in systematic reviews of interventions. Cochrane Database Syst Rev. 2010;12:MR000028.

26. Petticrew M, Tugwell $P$, Kristjansson E, Oliver $S$, Ueffing $E$, Welch V. Damned if you do, damned if you don't: subgroup analysis and equity. J Epidemiol Community Health. 2012;66(1):95-8.

27. Sun X, Briel M, Walter SD, Guyatt GH. Is a subgroup effect believable? Updating criteria to evaluate the credibility of subgroup analyses. BMJ. 2010; 340:c117.

28. Oxman A, Guyatt GH. A Consumer's guide to subgroup analyses. Ann Intern Med. 1992;116:78-84.

29. Moher D, Liberati A, Tetzlaff J, Altman DG. Preferred reporting items for systematic reviews and meta-analyses: the PRISMA statement. Ann Intern Med. 2009;151(4):264.

30. Joanna Briggs Institute. Critical Appraisal Tools Adelaide: The University of Adelaide, 2018 [Available from: http://joannabriggs.org/research/criticalappraisal-tools.html.

31. Lamers F, Jonkers CC, Bosma H, Knottnerus JA, van Eijk JT. Treating depression in diabetes patients: does a nurse-administered minimal psychological intervention affect diabetes-specific quality of life and glycaemic control? A randomized controlled trial. J Adv Nurs. 2011;67(4): 788-99.

32. DeWalt DA, Malone RM, Bryant ME, Kosnar MC, Corr KE, Rothman RL, et al. A heart failure self-management program for patients of all literacy levels: a randomized, controlled trial [ISRCTN11535170]. BMC Health Serv Res. 2006;6:30.

33. Thom DH, Ghorob A, Hessler D, De Vore D, Chen E, Bodenheimer TA. Impact of peer health coaching on glycemic control in low-income patients with diabetes: a randomized controlled trial. Ann Fam Med. 2013;11(2):137-44

34. Rothman RL, Malone R, Bryant B, Shintani AK, Crigler B, Dewalt DA, et al. A randomized trial of a primary care-based disease management program to improve cardiovascular risk factors and glycated hemoglobin levels in patients with diabetes. Am J Med. 2005;118(3):276-84.

35. Smeulders ES, van Haastregt JC, van Hoef EF, van Eijk JT, Kempen Gl. Evaluation of a self-management programme for congestive heart failure patients: design of a randomised controlled trial. BMC Health Serv Res. 2006;6:91.

36. Murray E, Sweeting M, Dack C, Pal K, Modrow K, Hudda M, et al. Web-based self-management support for people with type 2 diabetes (HeLP-diabetes): randomised controlled trial in English primary care. BMJ Open. 2017;7(9): e016009.

37. Day MA, Thorn BE. The relationship of demographic and psychosocial variables to pain-related outcomes in a rural chronic pain population. Pain. 2010;151(2):467-74. 
38. Boult C, Reider L, Leff B, Frick K, Boyd C, Wolff J, et al. The effect of guided care teams on the use of health services results from a cluster-randomized controlled trial. Arch Intern Med. 2011;171(5):460-6.

39. Nour K, Laforest S, Gauvin L, Gignac M. Behavior change following a selfmanagement intervention for housebound older adults with arthritis: An experimental study. Int J Behav Nutr Phys Act. 2006;3:12.

40. Angele AGCJ, Comijs HC, Kees CPMK, Deeg DJH. Benefits for elders with vulnerable health from the chronic disease self-management program (CDSMP) at short and longer term. BMC Geriatr. 2015;15:101.

41. Dattalo M, Giovannetti ER, Scharfstein D, Boult C, Wegener S, Wolff JL, et al. Who participates in chronic disease self-management (CDSM) programs? Differences between participants and nonparticipants in a population of multimorbid older adults. Med Care. 2012;50(12):1071-5.

42. Cauch-Dudek K, Victor JC, Sigmond M, Shah BR. Disparities in attendance at diabetes self-management education programs after diagnosis in Ontario, Canada: a cohort study. BMC Public Health. 2013;13:85.

43. Adjei Boakye E, Varble A, Rojek R, Peavler O, Trainer AK, Osazuwa-Peters N, et al. Sociodemographic factors associated with engagement in diabetes self-management education among people with diabetes in the United States. Public Health Rep. 2018;133(6):685-91.

44. Santorelli ML, Ekanayake RM, Wilkerson-Leconte L. Participation in a diabetes self-management class among adults with diabetes, New Jersey 2013-2015. Prev Chronic Dis. 2017;14:E63.

45. Horrell LN, Kneipp SM, Ahn S, Towne SD Jr, Mingo CA, Ory MG, et al. Chronic disease self-management education courses: utilization by lowincome, middle-aged participants. Intern. 2017;16:1-10.

46. Glasgow RE, Strycker LA, Kurz D, Faber A, Bell H, Dickman JM, et al. Recruitment for an internet-based diabetes self-management program: scientific and ethical implications. Ann Behav Med. 2010;40(1):40-8.

47. Poduval S, Ahmed S, Marston L, Hamilton F, Murray E. Crossing the digital divide in online self-management support: analysis of usage data from HeLP-diabetes. JMIR Diabetes. 2018:3(4):e10925.

48. Bayliss EA, Ellis JL, Steiner JF. Barriers to self-management and quality-of-life outcomes in seniors with multimorbidities. Ann Fam Med. 2007:5(5):395402.

49. Hardman R, Lawn S, Tsourtos G. Pain self-management: easier said than done? Factors Associated with Early Dropout from Pain Self-Management in a Rural Primary Care Population. Pain Med. 2018:06:06.

50. Kure-Biegel N, Schnohr CW, Hindhede AL, Diderichsen F. Risk factors for not completing health interventions and the potential impact on health inequalities between educational groups - a mixed method study from Denmark. Intern. 2016;15:54.

51. Thorn BE, Day MA, Burns J, Kuhajda MC, Gaskins SW, Sweeney K, et al. Randomized trial of group cognitive behavioral therapy compared with a pain education control for low-literacy rural people with chronic pain. Pain. 2011;152(12):2710-20.

52. Schulman-Green D, Jaser SS, Park C, Whittemore R. A metasynthesis of factors affecting self-management of chronic illness. J Adv Nurs. 2016;72(7): 1469-89.

53. DeWalt DA, Schillinger D, Ruo B, Bibbins-Domingo K, Baker DW, Holmes GM, et al. Multisite randomized trial of a single-session versus multisession literacy-sensitive self-care intervention for patients with heart failure. Circulation. 2012;125(23):2854-62

54. Powell LH, Calvin J, Richardson D, Janssen I. Mendes de Leon C, Flynn K, et al. self-management counseling in patients with heart failure: the heart failure adherence and retention randomised controlled trial. JAMA Intern Med. 2010;304(12):1331-8.

55. Govil SRMPH, Weidner GP, Merritt-Worden TMS, Ornish DMD. Socioeconomic status and improvements in lifestyle, coronary risk factors, and quality of life: the multisite cardiac lifestyle intervention program. Am J Public Health. 2009;99(7):1263-70

56. Moskowitz D, Thom DH, Hessler D, Ghorob A, Bodenheimer T. Peer coaching to improve diabetes self-management: which patients benefit most? J Gen Intern Med. 2013;28(7):938-42.

57. Rothman R, DeWalt D, Malone R, Bryant B, Shintani A, Crigler B, et al. Influence of patient literacy on the effectiveness of a primary care-based diabetes disease management program. JAMA Intern Med. 2004;292(14): 1711-6.

58. Bosma H, Lamers F, Jonkers CCM, Van Eijk JT. Disparities by education level in outcomes of a self-management intervention: the DELTA trial in the Netherlands. Psychiatr Serv. 2011;62(7):793-5.
59. Merius HN, Rohan AJ. An integrative review of factors associated with patient attrition from community health worker programs that support diabetes self-care. J Community Health Nurs. 2017;34(4):214-28.

60. Sokol R, Fisher E. Peer support for the hardly reached: a systematic review. Am J Public Health. 2016;106(7):e1-8.

61. Dennis SM, Harris M, Lloyd J, Powell Davies G, Faruqi N, Zwar N. Do people with existing chronic conditions benefit from telephone coaching? A rapid review. Aust Health Rev. 2013;37(3):381-8.

62. Roberts SR, Crigler J, Ramirez C, Sisco D, Early GL. Working with socially and medically complex patients: when care transitions are circular, overlapping, and continual rather than linear and finite. J Healthc Qual. 2015;37(4):245-65.

63. Warsi A, Wang P, LaValley M, Avorn J, Solomon D. Self-management education programs in chronic disease: a systematic review and methodological critique of the literature. Arch Intern Med. 2004;164:1641-9.

64. Smeulders ES, van Haastregt JC, Ambergen T, Stoffers HE, Janssen-Boyne JJ, Uszko-Lencer $\mathrm{NH}$, et al. Heart failure patients with a lower educational level and better cognitive status benefit most from a self-management group programme. Patient Educ Couns. 2010;81(2):214-21.

65. Sarkar U, Fisher $L$, Schillinger D. Is self-efficacy associated with diabetes selfmanagement across race/ethnicity and health literacy? Diabetes Care. 2006; 29(4):823-9.

66. Glass T, Kress A, Berkman L. Experimental psychosocial interventions. In: Berkman L, Kawachi I, Glymour M, editors. Social Epidemiology. 2nd ed. New York: Oxford University Press; 2014.

67. Blackstock F, ZuWallack R, Nici L, Lareau S. Why Don't our patients with chronic obstructive pulmonary disease listen to us? The enigma of nonadherence. Ann Am Thor Soc. 2016;13(3):317-23.

68. Norris SN, Nichols PJ, Caspersen C, Glasgow R, Engelgau M, Jack L, Isham G, Snyder S, Carande-Kulis V, Garfield S, Briss P, McCulloch D. The effectiveness of disease and case Management for People with diabetes: a systematic review. Am J Prev Med. 2002;22(4S):15-38.

69. Hinder SG, Greenhalgh T. "This does my head in". Ethnographic study of self-management by people with diabetes. BMC Health Serv Res. 2012;12:83.

70. Gallagher R, Warwick M, Chenoweth L, Stein-Parbury J, Milton-Wildey K. Medication knowledge, adherence and predictors among people with heart failure and chronic obstructive pulmonary disease. J Nurs Healthcare Chronic Illnesses. 2011:3(1):30-40.

71. Debussche $X$. Is adherence a relevant issue in the self-management education of diabetes? A mixed narrative review. Diabetes Metab Syndr Obes. 2014;7:357-67.

72. Jerant AF, von Friederichs-Fitzwater MM, Moore M. Patients' perceived barriers to active self-management of chronic conditions. Patient Educ Couns. 2005;57(3):300-7.

73. Boehmer KR, Dabrh AMA, Gionfriddo MR, Erwin P, Montori VM. Does the chronic care model meet the emerging needs of people living with multimorbidity? A systematic review and thematic synthesis. PLOS ONE. 2018;13(2) (no pagination)):e0190852.

74. Cramm JM, Nieboer AP. Self-management abilities, physical health and depressive symptoms among patients with cardiovascular diseases, chronic obstructive pulmonary disease, and diabetes. Patient Educ Couns. 2012; 87(3):411-5.

75. Campbell DJT, Ronksley PE, Manns BJ, Tonelli M, Sanmartin C, Weaver RG, et al. The Association of Income with Health Behavior Change and Disease Monitoring among Patients with Chronic Disease. PLoS One. 2014;9(4): e94007.

76. Coventry PA, Fisher L, Kenning C, Bee P, Bower P. Capacity, responsibility, and motivation: a critical qualitative evaluation of patient and practitioner views about barriers to self-management in people with multimorbidity. BMC Health Serv Res. 2014:14:536.

77. Shippee ND, Shah ND, May CR, Mair FS, Montori VM. Cumulative complexity: a functional, patient-centered model of patient complexity can improve research and practice. J Clin Epidemiol. 2012;65(10):1041-51.

\section{Publisher's Note}

Springer Nature remains neutral with regard to jurisdictional claims in published maps and institutional affiliations. 